\title{
Influencing Factors of Social Service Satisfaction of the Elderly under the Background of Internet Attention
}

\author{
Miao Lin (i) \\ School of Humanities, Zhuhai City Polytechnic, Zhuhai 519090, China \\ Correspondence should be addressed to Miao Lin; 201714010017@zknu.edu.cn
}

Received 26 March 2021; Accepted 23 April 2021; Published 3 May 2021

Academic Editor: Huihua Chen

Copyright (C) 2021 Miao Lin. This is an open access article distributed under the Creative Commons Attribution License, which permits unrestricted use, distribution, and reproduction in any medium, provided the original work is properly cited.

\begin{abstract}
Improving the life service for the elderly is a topic of great concern to the government and society. This paper explores the influence of net attention on social work service satisfaction of the elderly. This paper studies and analyzes the current situation of the elderly's net attention and social satisfaction, constructs the index system of social service satisfaction through the sample data of 17 districts and counties in A province, and establishes a multilayer linear model to analyze the influencing factors of social service satisfaction, and empirically analyzes the feasibility of the proposed model's rationality and effectiveness. The structure shows that the scores of elderly people's satisfaction with public services in all regions of A province are higher than 60 points, and the biggest difference of standard deviation of each region is 3.91 points. Public service expenditure has a negative effect on social service satisfaction, but population density, geographical location, and per capita GDP have no obvious effect. The regression coefficient of public service expenditure is -0.099134 , which can reduce the score of social service satisfaction. Elderly participation in public welfare activities, elderly awareness of government, and elderly participation in government can improve the social service satisfaction score.
\end{abstract}

\section{Introduction}

At present, China is one of the countries with the largest number of elderly people in the world and also one of the countries with the most serious population aging [1]. Compared with other social groups, Internet attention, as a social resource, has a great impact on the life of the elderly. It can not only help the elderly enrich their life and increase their enjoyment of life but also give them a certain degree of spiritual comfort [2]. The continuous development of Internet technology has brought great convenience to people's lives and put forward higher requirements for people's ability to accept new things [3]. Before the advent of the Internet era, there are many defects in China's current pension problems, mainly due to the lack of transparency and different standards, especially in poor rural areas, where farmers are unable to obtain the first resource information and the information lags behind seriously. At the same time, the elderly who really need the attention of the government and society can not get timely help, resulting in waste of resources and unreasonable resource matching. Although the new functions such as appointment registration, online payment, online shopping, and mobile payment are constantly realized, the life of the elderly has encountered a lot of inconveniences. At this stage, the whole society ensures that the life of the elderly is not marginalized through path guarantee, group cultivation, market mode, knowledge popularization, ideology, and other aspects [4]. In addition, government departments also promote the fair use and optimal allocation of information resources through the role of promotion and guidance of relevant policies.

In order to solve the problem of social service satisfaction of the elderly, Marmo $s$ team investigated 203 elderly people with hospice care through interviews, including professional experience, hospice care characteristics, interdisciplinary collaboration, perception of leadership, and internal and external job satisfaction, and finally found that the current elderly people have higher social satisfaction [5]. Utz and Breuer, through six longitudinal studies on Internet users in the Netherlands, first examined whether there are 
differences in social support and well-being between users of social networking sites and nonusers of social networking sites and analyzed the number of people seeking advice and close contact on social networking sites. Finally, we found that most of the Internet users are influenced by social networking sites People's well-being has a certain impact, which can help people enrich their leisure time at [6]. In order to explore the relationship between society satisfaction and resilience, self-efficacy and social support of middleaged and elderly people in the Kermanshah area of Iran, Dan et al. investigated 240 people with general self-efficacy, Connor Davidson Resilience Scale, specter job satisfaction scale, and multidimensional social support scale by convenient sampling. The results showed that middle-aged and elderly people's social satisfaction was high. They were very supportive and satisfied with social service [7]. In order to explore the mediating mechanism of self-efficacy and life balance and how family enrichment can promote social service satisfaction, Chan team used a structural equation model to collect data from four different groups of Australians for 12 months. The results showed that self-efficacy has a good role in promoting social service satisfaction [8]. In order to understand the influencing factors of social psychological satisfaction of the elderly, experts such as Lizano conducted a cross-sectional data study on 68 Salvadoran social ers. The results showed that the relationship between family conflict and mental health was stronger among people with low social satisfaction [9].

In order to describe the social representation of the Internet of the elderly and compare the objectification and anchoring process of different levels of the elderly in the use of the Internet, Castro team used a combination of qualitative and quantitative research methods, descriptive and comparative design methods to collect data from 40 subjects, and used different tools. The results showed that the number of the elderly online increased, which was related to the continuous growth of the elderly population. Growth also has a direct impact [10]. Mamo and other experts used SERVQUAL model to measure social service satisfaction through the service quality dimension in order to evaluate the influencing factors of service quality in Dao Luo area of ethio Telecom. Descriptive statistical tools, tables, frequencies, and percentages were used for data analysis. The study found that the factors affecting social service satisfaction have an impact on service quality [11].

In order to explore the community service satisfaction of the elderly, scholars such as Yung et al. used the ordered probit model and binary logistic regression model to analyze the acceptability and comfort of the elderly. The results showed that the elderly were very satisfied with the urban planning of the community. The research results provide references and suggestions for the elderly in the future [12]. In order to compare the impact of health care and specific workrelated factors of community social workers on social service satisfaction of the elderly, Nursalam and others conducted a questionnaire survey on service quality of the elderly in Indonesian community. The results showed that the elderly were highly satisfied with the welfare benefits provided by the community, the nursing form of the elderly, and the service attitude of the community staff [13]. In order to prove that the elderly's social service satisfaction is of great significance to achieve a good social environment in good public services, park and others used the method of combining quantitative and survey methods and the data obtained from the tested validity and reliability questionnaire. This study takes professionalism as the independent variable, elderly assets as the dependent variable, and responsiveness as the intervention variable. The results show that elderly satisfaction can promote the positive development of social public services [14]. In order to explore the service satisfaction of the elderly detected by international standardized ratio nursing points in a community pharmacy environment, Beyene and other experts analyzed the influence of age, pharmacy times, race, distance to pharmacy, health status, and other factors on the satisfaction of the elderly [15].

To sum up, there are many researches on Internet attention and social satisfaction of the elderly at home and abroad, and gratifying results have been achieved. However, there is little data mining analysis on the correlation between the two, and there is no impact analysis model and evaluation model of social service satisfaction around the world. The research consists of four parts. The second part mainly introduces the current situation of the elderly Net attention and social satisfaction. The third part constructs the social service satisfaction evaluation system and proposes the corresponding evaluation model. The fourth part tests the reliability of the model through empirical analysis. The fifth part summarizes the research results and puts forward the shortcomings in the research process.

\section{The Status Quo of Internet Attention and Social Satisfaction of the Elderly under the Background of Big Data}

2.1. Internet Concerns of the Elderly in the Context of Big Data. Social for the elderly is a kind of professional service activity in response to the problems of the elderly. Under the guidance of professional values, it refers to the professional service activities in which social ers who are professionally trained make full use of the theories and methods of social to solve problems and get rid of difficulties for the elderly who suffer from various difficulties and temporarily lose their social functions in life, and at the same time promote more elderly people to get further development in their later years. This paper studies and analyzes the correlation between the elderly Net attention and social service satisfaction, and the data mining flow chart is shown in Figure 1. First of all, we collect the data of the elderly online attention, including the Baidu Index and the type and quantity report of the elderly online attention. Then, the net data mining is carried out to mine the correlation between social service satisfaction and net attention. Baidu Index is a comprehensive analysis platform to process and analyze massive Internet users' behavior data of Baidu. It is one of the most important comprehensive platforms in the era of Internet and big data. Its main functions are crowd portrait, demand map, crowd attribute, industry trend, and single word trend analysis. 


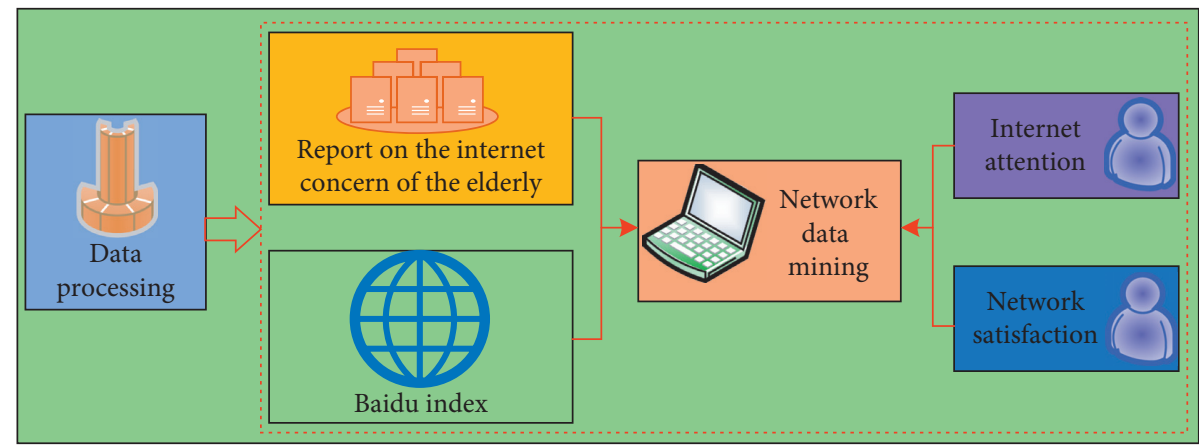

FIGURE 1: Mining the correlation between the elderly's Internet attention and social service satisfaction.

The elderly's net attention refers to the elderly's attention to net information. Figure 2 shows the number and penetration rate of Internet access for the elderly in China from 2014 to 2019. In the five years from 2014 to 2019 , the number of elderly Internet users in China is $7.1 \times 107,8 \times 107,9.2$ $\times 107,10.7 \times 107,12.4 \times 107$, and $14.6 \times 107$, respectively. The corresponding proportion of Internet users is $4.98 \%$, $5.21 \%, 5.51 \%, 6.78 \%, 7.93 \%$, and $8.36 \%$, and the penetration rate is about $10 \%$. According to the big health industry insight report 2019, in 2017, the number of elderly Internet users rapidly exceeded 100 million, and the proportion of elderly Internet users in the overall Internet users in 2017 was $12.6 \%$. The report was launched by Tencent News Contech data lab and Tencent advertising. According to the report, more than $90 \%$ of the elderly spend more than one hour online on average every day, and more than half of the elderly use mobile phones for more than two hours. The content and proportion of elderly people's online attention are shown in Figure 3(a). Tourism and leisure, singing and listening to songs, online shopping, reading news, watching videos, and social chat accounted for $23 \%, 30 \%, 30 \%, 41 \%$, $44 \%$, and $67 \%$, respectively. More than $80 \%$ of the middleaged and old people can master the basic functions of WeChat, such as sending and receiving red packets, browsing the circle of friends, sending expression packets, and so on. There are many types of apps used by the elderly, including games, social networking, reading, video, shopping, financial management, travel, music, life, education, photo photography, health, and tourism.

The elderly Internet life research report shows that the elderly attach great importance to the topic of health and national affairs. At present, there are two ways for the elderly to acquire health knowledge; one is the interpersonal relationship; the other is the way of transmission. The former can be divided into community population, doctors, and acquaintances, with corresponding proportions of $18 \%$, $43 \%$, and $47 \%$, respectively. The latter includes traditional paper media, TV programs, and the Internet, with corresponding proportions of $14 \%, 30 \%$, and $44 \%$, respectively. The corresponding types and proportions of health knowledge acquisition are shown in Figure 3(b). At the same time, the top three types of deception information for the elderly were discount group buying goods, free mobile phone flow, and free red envelope, with corresponding

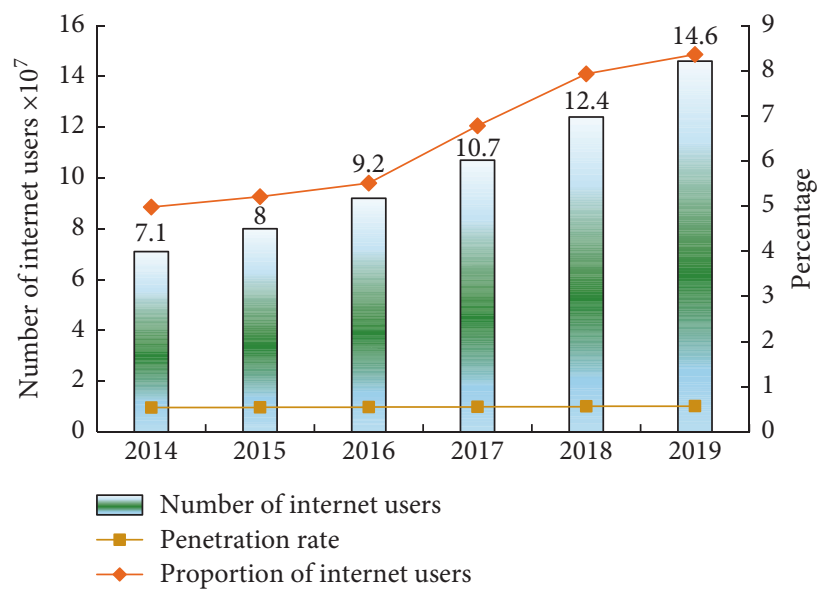

Figure 2: Number and penetration rate of Internet access for the elderly from 2014 to 2019 .

proportions of $48.6 \%, 52.3 \%$, and $60.3 \%$, respectively. Among the cheated old people, the middle and high income old people account for a large proportion.

\subsection{Social Work Service Satisfaction of the Elderly under the} Background of Big Data. The research content of social satisfaction includes satisfaction connotation, satisfaction influencing factors, satisfaction evaluation model, and satisfaction measurement model. In the research, social service satisfaction refers to the elderly's evaluation of the quality and performance of basic services provided by the community [16]. Referring to the classic national customer satisfaction index model and combining it with the relevant characteristics of community service, this paper creates the social service satisfaction evaluation model, and the specific information is shown in Figure 4. The evaluation model includes seven aspects, namely, perceived value, public participation, access to community service, community service mode, public expectation, perceived quality, and community service elements. Public participation, community service access, community service mode, and community service elements affect the perceived quality of community service. Perceived quality is the community service after the evaluation of community service. Community service elements mainly refer to community service 


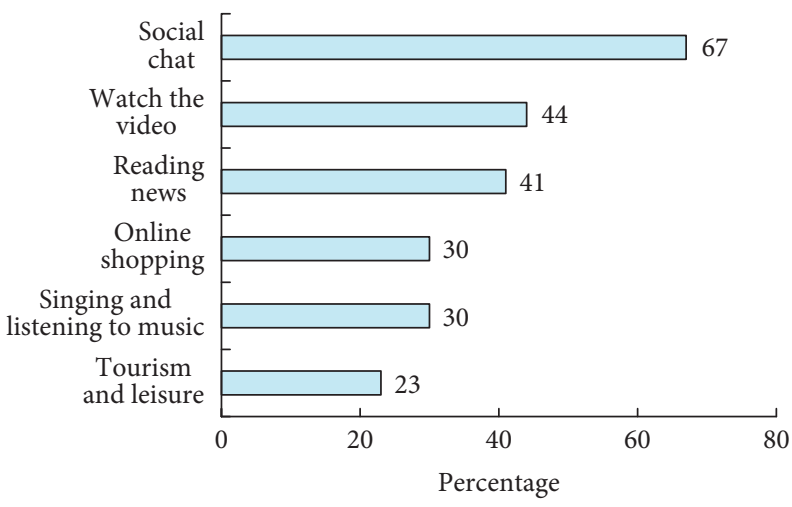

(a)

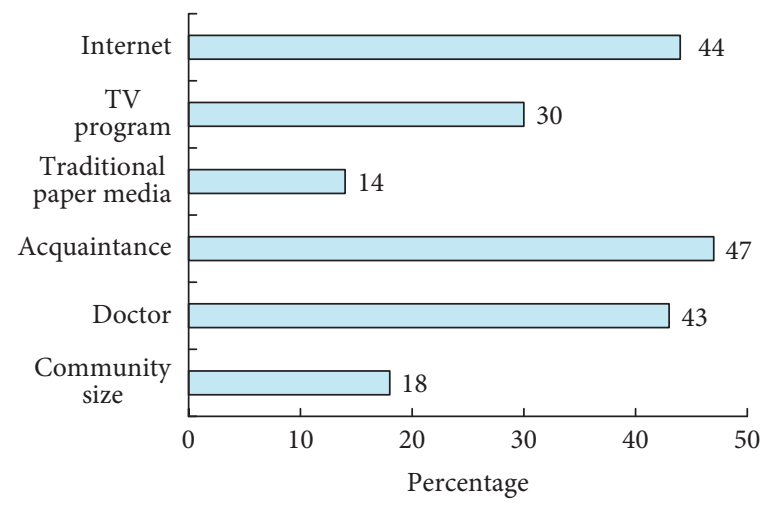

(b)

Figure 3: The type and proportion of elderly people's online attention to content and access to health knowledge. (a) Content and proportion of elderly people's online attention. (b) The corresponding types and proportions of knowledge acquisition.

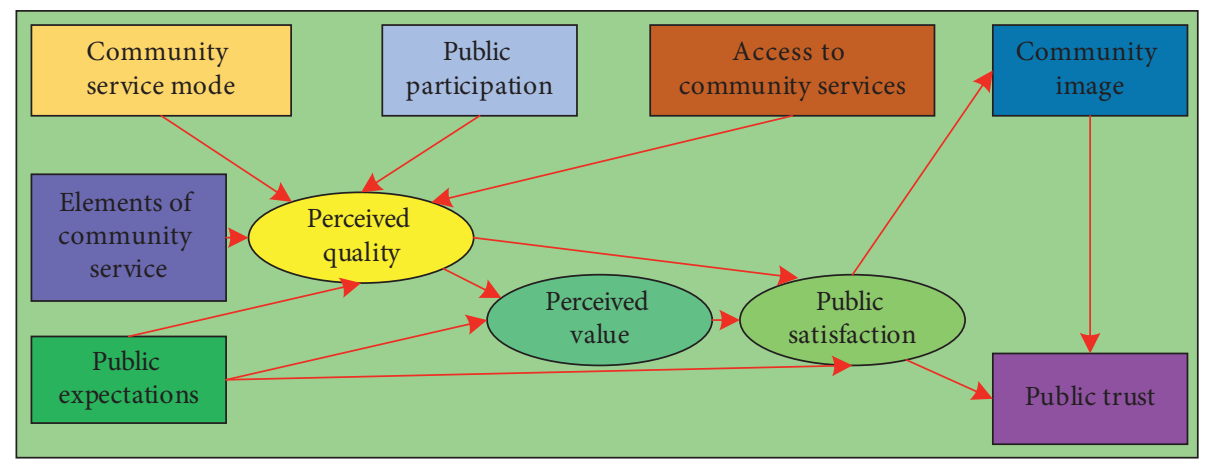

Figure 4: Evaluation model of social service satisfaction.

projects, community service teams, community service facilities, and community service institutions. Public participation refers to the response speed of the public when using community services. The access to community services refers to the frequency of the public using community services and the situation of obtaining and using the services. The way of community services refers to the response speed and operation mechanism of carrying out specific community projects. Perceived value is the sum of all values in the whole process of public perception and contact with community services [17]. Public satisfaction represents the gap between the expected and actual use of community services, followed by psychological perception. The measurement of social service satisfaction includes public trust and community image.

\section{Evaluation Model of Social Service Satisfaction}

3.1. Index Selection. The influencing factors of social service satisfaction include the following four aspects: economics, social psychology, sociology, and politics. The economic research approach assumes that the famous rational economic man is established and points out that citizens should evaluate social service satisfaction under the condition of maximizing interests. The social psychological approach emphasizes the individual's psychological sense of belonging in a specific social group and attaches great importance to the individual's adaptation to the environment and cognitive level [18]. According to sociological determinism, the core influencing factors of satisfaction evaluation and political attitude are the basic characteristics of individuals. At the same time, political factors such as the government's trust, public participation, government information disclosure, and government efficiency can affect social service satisfaction. The specific quantitative indicators can be divided into individual and social levels. The study sets the following two points: subjective factors are the most important factors affecting the satisfaction of public services in all districts and counties, and objective factors affect the satisfaction of public services to a certain extent.

In view of the above analysis, combined with the livelihood satisfaction survey project of A province in 2018, the social service satisfaction index system is constructed. The evaluation model of social service satisfaction is shown in Figure 5, including 8 first level indicators and 16 second level indicators. The first level indicators include efficiency, the rule of law, culture and sports, environment, transportation, housing, medical care, and education, while the second level indicators include evaluation of compulsory education teaching quality and balanced allocation of educational resources. The secondary indicators of medical care include 
the evaluation of community hospital and family doctor service and hospital medical level. The secondary indicators of housing include the allocation and construction of indemnificatory housing and the transformation of the old city by the government. The secondary indicators of transportation include the evaluation of the convenience and coverage of public transportation and the smoothness and quality of urban roads [19]. The secondary indicators of the environment include the evaluation of urban air quality and urban green maintenance. The secondary indicators of culture and sports include the evaluation of services provided by venues such as cultural activity centers and public leisure venues. The secondary indicators of the rule of law include the evaluation of the social security environment and the fairness and civilization of administrative law enforcement. The secondary indicators of efficiency include the evaluation of the satisfaction of government agencies in dealing with public services, including control variables and explanatory variables in order to meet the needs of the multilevel linear model [20]. Control variables are subjective variables, which involve the participation level of public welfare activities, the participation of government, the familiarity of government, and demographic variables such as registered residence, income, political background, and gender. The explanatory variable is a kind of descriptive variable to measure the objective level, involving the fiscal expenditure of each district and county government and per capita GDP in the population density, geographical location, and public services of each district and county. At the same time, they are combined with spss 22.0 analysis software and multifactor statistical method to determine the weight of each index. The data source of the study is the public satisfaction survey of the elderly in A province in 2018. The sample is from 5106 elderly people in 17 districts and counties of the city. The survey uses stratified sampling and the PPS sampling method to obtain 5100 effective samples, which ensure that the sample has good representativeness in economic income, education level, gender ratio, age, etc.

This paper uses hlm6.08 to analyze the correlation between subjective and objective factors and social service satisfaction. In the absence of any independent variables, zero model analysis is needed. The process of zero model analysis includes the first layer model, the second layer model, and the mixed model. In order to calculate the proportion of the second level of social service satisfaction of the elderly in the overall variation, the cross level correlation coefficient was determined. The value of the coefficient is in the range of 0 and 1 . The smaller the value is, the smaller the influence of objective factors is. At the same time, for the influence factors of objective factors and specific variables in subjective factors, the study needs to introduce subjective variables and objective variables to create a complete model. The formula of the mixed model is as follows:

$$
\begin{aligned}
Y= & B 0+B 1 * a+B 3 * b+B 4 * c+B 5 * d \\
& +B 6 * e+B 7 * f+B 8 * g+B 9 * h+B 10 * i+R .
\end{aligned}
$$

In equation (1), $B 0$ refers to the subjective variable, $R$ refers to the random error, $B 1-B 10$ all refer to the corresponding variable parameters, and each corresponds to G10, G20, G30, G40, G50, G60, G70, G80, G90, G100. $a-i$ refers to gender, age, education level, occupation, monthly income, political background, household registration, elderly people's participation in government, elderly people's awareness of the government, and elderly people's participation in public welfare activities. In the second level model, $G 00-G 04$, respectively, refer to the corresponding parameter values of the initial value, population density, location, gross domestic product (GDP) per capita, and public service fiscal expenditure. This paper studies the use of robust standard error for multilevel linear model regression analysis, which can not only ensure the stability of variables but also prevent the occurrence of multicollinearity.

3.2. Key Technologies of Multiline Model. Multilayer linear model includes two forms: complete model and zero model; the basic form of the individual layer of the zero model is as follows:

$$
y=\beta_{0}+\gamma .
$$

The second layer is the group layer

$$
\beta_{0}=\eta_{00}+\mu_{0} \text {. }
$$

In equations (2) and (3), $\gamma$ represents the residual of the first layer, $\eta_{00}$ represents the intercept of the group layer, $\beta_{0}$ represents the intercept of the individual layer, and $\mu_{0}$ represents the residual of the group layer.

For the complete model, it contains its own independent variables at the individual level and the group level, so it can explain the overall differences of the dependent variables through the model. Let the dependent variable of the individual layer be $y$ and $\beta_{i}$ be the coefficient of regression equation of the individual layer

$$
y=\beta_{0}+\sum_{i=1}^{N} \beta_{i} \chi_{i}+\gamma .
$$

Let $\beta_{i 0}$ denote the $i-t h$ intercept of the regression equation at the population level, $\omega_{j}$ denote the independent variable at the population level, and $\mu_{i}$ denote the $i-t h$ residual at the population level. The basic forms of the group layer are as follows:

$$
\begin{aligned}
& \beta_{1}=\eta_{10}+\sum_{j=1}^{M} \eta_{1 j} \omega_{j}+\mu_{1}, \\
& \beta_{2}=\eta_{20}+\sum_{j=1}^{M} \eta_{2 j} \omega_{j}+\mu_{2}, \\
& \beta_{N}=\eta_{N 0}+\sum_{j=1}^{M} \eta_{N j} \omega_{j}+\mu_{N} .
\end{aligned}
$$

Let $\gamma_{i j}$ denote the random effect at level 1 and $\mu_{0 j}$ denote the random effect at level 2 : 


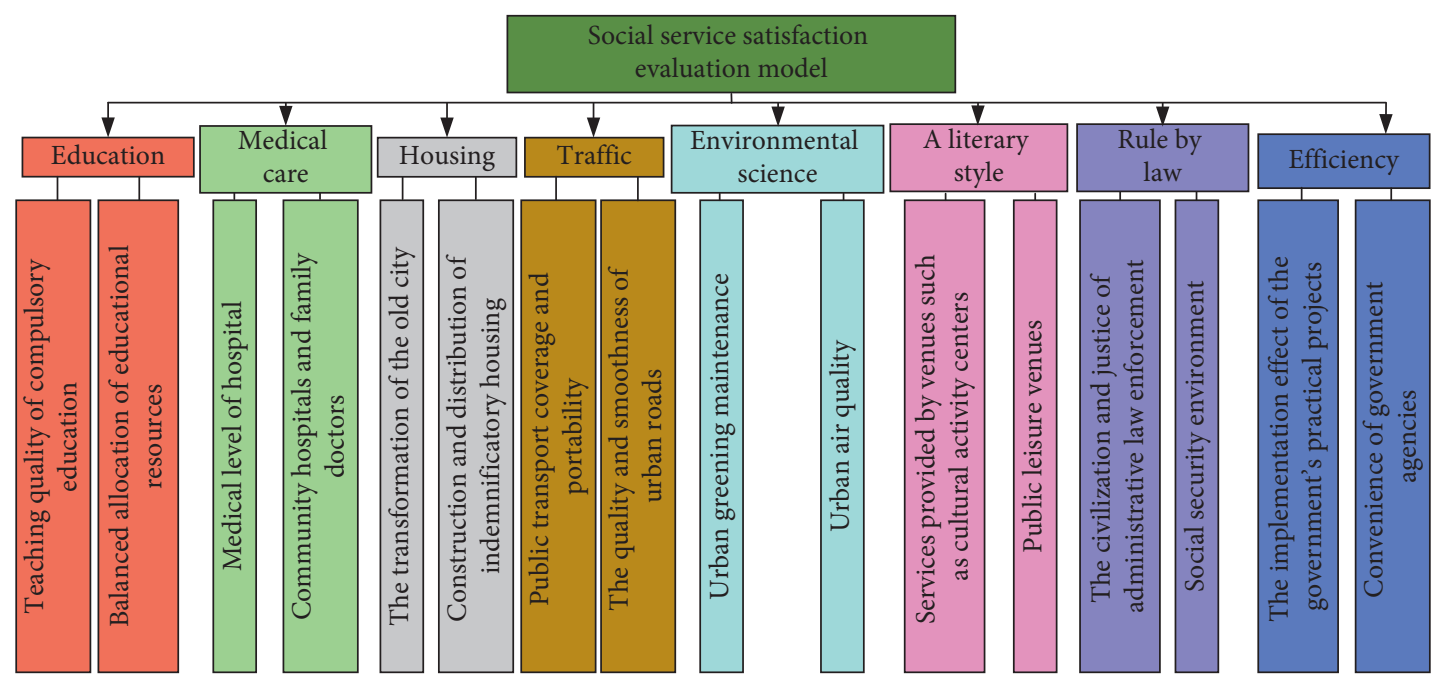

FIgURE 5: A model of influencing factors of social service satisfaction.

$$
\begin{aligned}
& y_{i j}=\beta_{0 j}+\beta_{1 j} \chi_{i j}+\gamma_{i j}, \\
& \beta_{0 j}=\eta_{00}+\mu_{0 j}, \\
& \beta_{1 j}=\eta_{10}+\mu_{1 j} .
\end{aligned}
$$

If level 1 intercept random variation is allowed in the model, model 2 can be expressed as follows:

$$
\beta_{1 j}=\eta_{10}
$$

If the intercept in Level 2 is allowed to change randomly, level 1 can indicate the following:

$$
y_{i j}=\beta 0_{j}+\gamma_{i j}
$$

The variance $\operatorname{var}\left(y_{i j}\right)$ corresponding to $y_{i j}$ can be decomposed into the following:

$$
\operatorname{var}\left(y_{i j}\right)=\operatorname{var}\left(\mu_{o j}\right)+\gamma_{i j}=\tau_{00}+\sigma^{2} .
$$

The model does not consider the influence of predictive variables on dependent variables at each level. Let $\sigma^{2}$ and $\tau_{00}$ represent the variation of level 1 and level 2, respectively, and the overall variation can be explained by level 2 :

$$
\rho=\frac{\tau_{00}}{\tau_{00}+\sigma^{2}} .
$$

For the test of fixed parameters, the following formula can be used for $Z$ test:

$$
Z=\frac{\widehat{\eta}_{p q}}{\left(V_{\widehat{\eta}_{p q}}\right)^{1 / 2}},
$$

where $\widehat{\eta}_{p q}$ is the maximum likelihood estimate of the fixed parameter and $V_{\hat{\eta}_{p q}}$ is the variance.

\section{Analysis of Empirical Results}

4.1. Descriptive Statistical Analysis of Social Service Satisfaction. The full score of social service satisfaction is 100 , and the qualified score is 60 . The weight of eight firstclass indicators of efficiency, the rule of law, culture and sports, environment, transportation, housing, medical treatment, and education is set as $0.1,0.1,0.2,0.1,0.1,0.1,0.2$, and 0.1 . The results of social service satisfaction of all districts and counties in A province are shown in Figure 6. As a whole, the elderly in A province are more satisfied with public services. The social service satisfaction score of $Q$ District was 72.90, N District was 70.93, L District was 70.78, and $J$ District was 70.47 . The social service satisfaction scores of these four regions ranked in the top four. $C$ District social service satisfaction score reached 65.97, Xuhui District social service satisfaction score reached 65.56, E District social service satisfaction score reached 65.51 , and $H$ District social service satisfaction score reached 64.77 . The social service satisfaction scores of the above four regions ranked the last four. The scores of 17 regions all reached 60, but there was a certain gap in the total score. At the same time, there is a certain gap in the standard deviation of satisfaction score. The standard deviation of 17 regions ranged from 9.72 to 13.63 .

The radar chart of the elderly's satisfaction with social services is shown in Figure 7. The scores of education, medical treatment, housing, transportation, environment, sports, the rule of law, and efficiency were 69.66, 66.69, 63.29, $67.98,66.99,68.97,69.55$, and 69.73 , respectively. There is a big gap in the social service satisfaction score of the eight first level indicators. It can be seen from the radar chart that the elderly have the lowest score on housing, followed by medical care. The highest score is government education and efficiency. Therefore, the government and society need to greatly promote the implementation and improvement of housing, medical and environmental policies and strive to provide more basic life security for the elderly. 


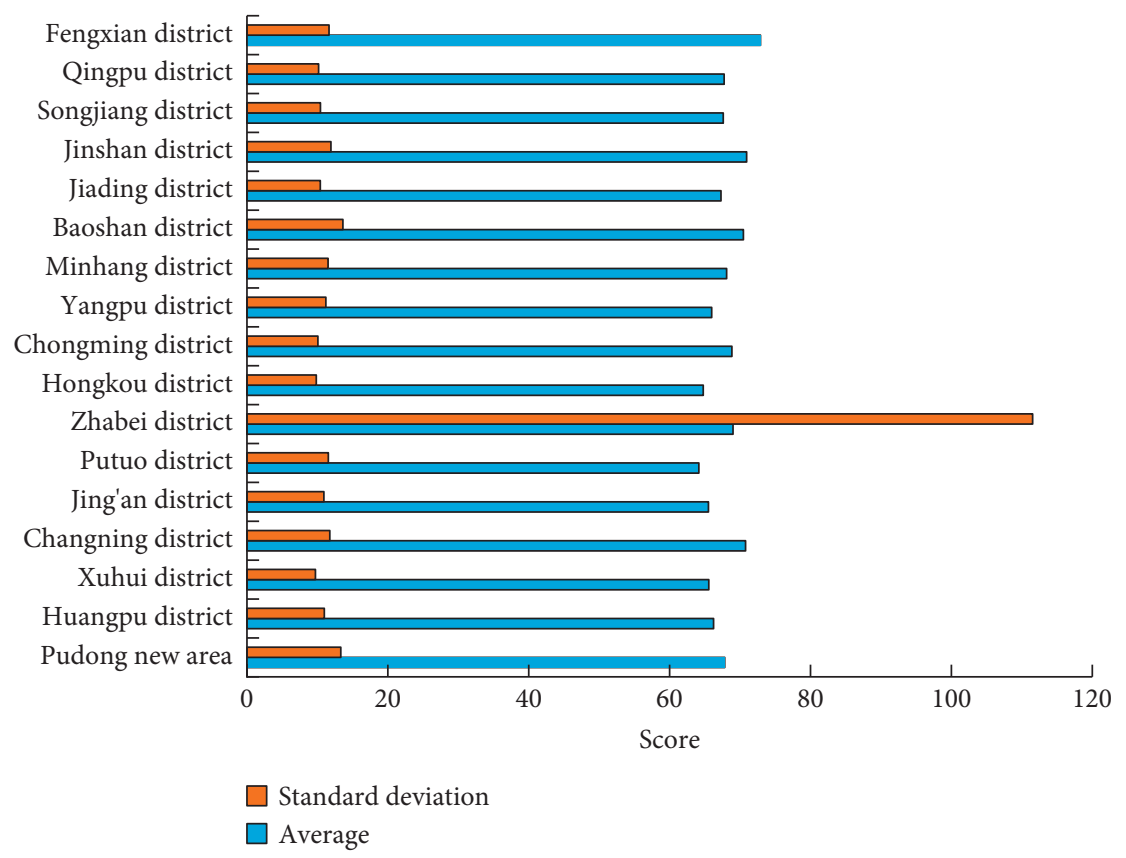

Figure 6: Social service satisfaction score of all districts and counties in A province.

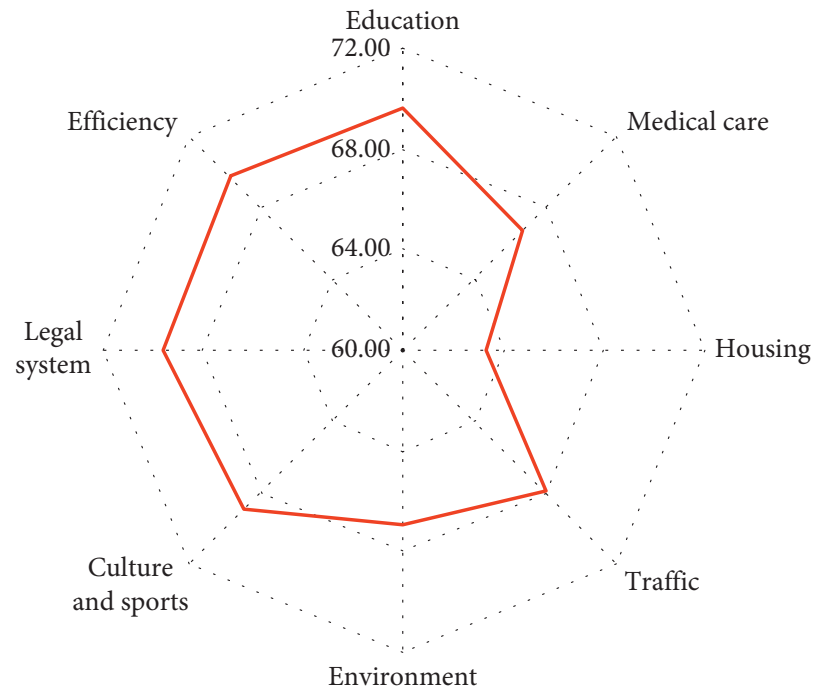

Figure 7: Radar chart of social service satisfaction score.

4.2. Analysis of Multilayer Linear Model. The subjective and objective variables are shown in Figures $8(a)$ and $8(\mathrm{~b})$. The number of samples collected at the subjective and objective levels was 4707 and 17, respectively. The maximum and minimum satisfaction of community service was 100 points and 20 points, respectively, the standard deviation was 11.47 points, and the average value was 67.86 points. The maximum and minimum of residents' participation in government are 13 and 0 , respectively, with the standard deviation of 3.69 and an average of 3.77. The maximum and minimum of residents' awareness of government were 13 points and 4.06 points, respectively, the standard deviation was 3.69 points, and the average was 3.77 points. The maximum and minimum of residents' participation in public welfare are 4 and 1 , respectively, the standard deviation is 1 , and the average is 2.59 . The maximum and minimum population densities are 35698 and 592 people/square kilometers, respectively, the standard deviation is 12951 people/square kilometers, and the average is 14420 people/square kilometers. The maximum and minimum values of per capita GDP are 2.945 billion yuan/10000 people and 388 million yuan/10000 people, respectively, the standard deviation is 679 million yuan/10000 people, and the average value is 1.048 billion yuan/10000 people. The maximum and minimum of public service expenditure were $40.7 \%$ and $17.22 \%$, respectively, the standard deviation was $6.83 \%$, and the average was $32.54 \%$. 


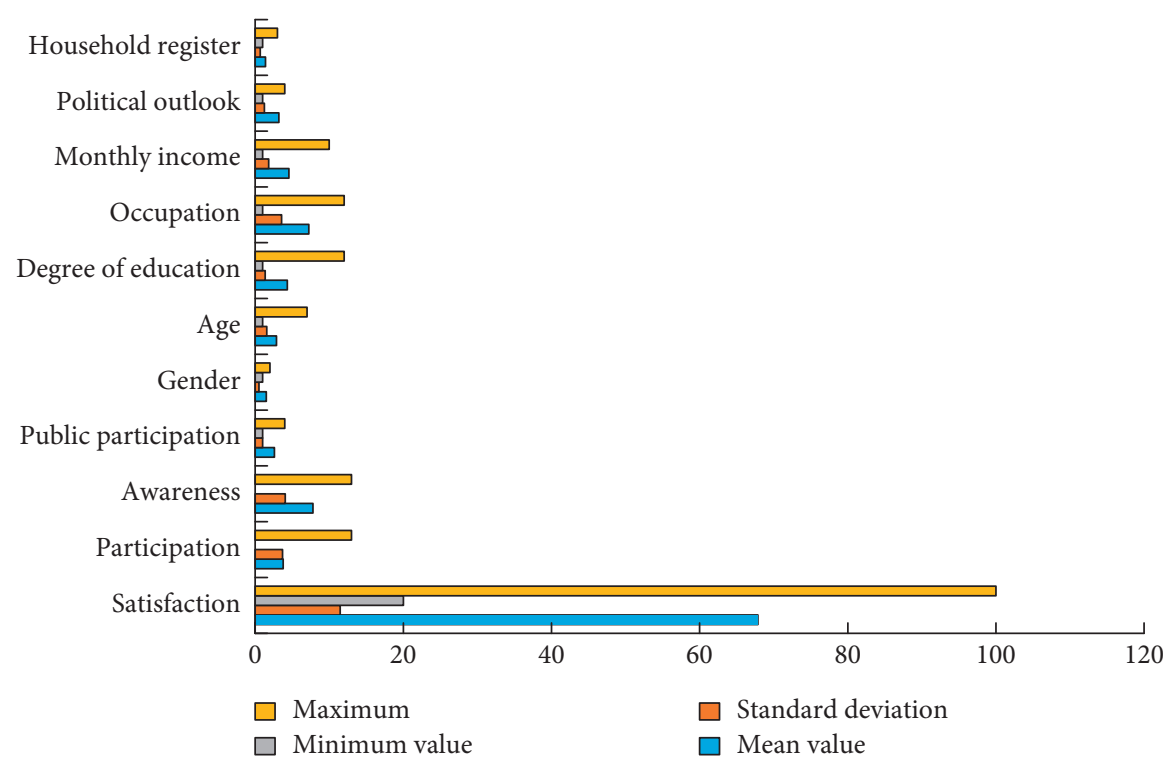

(a)

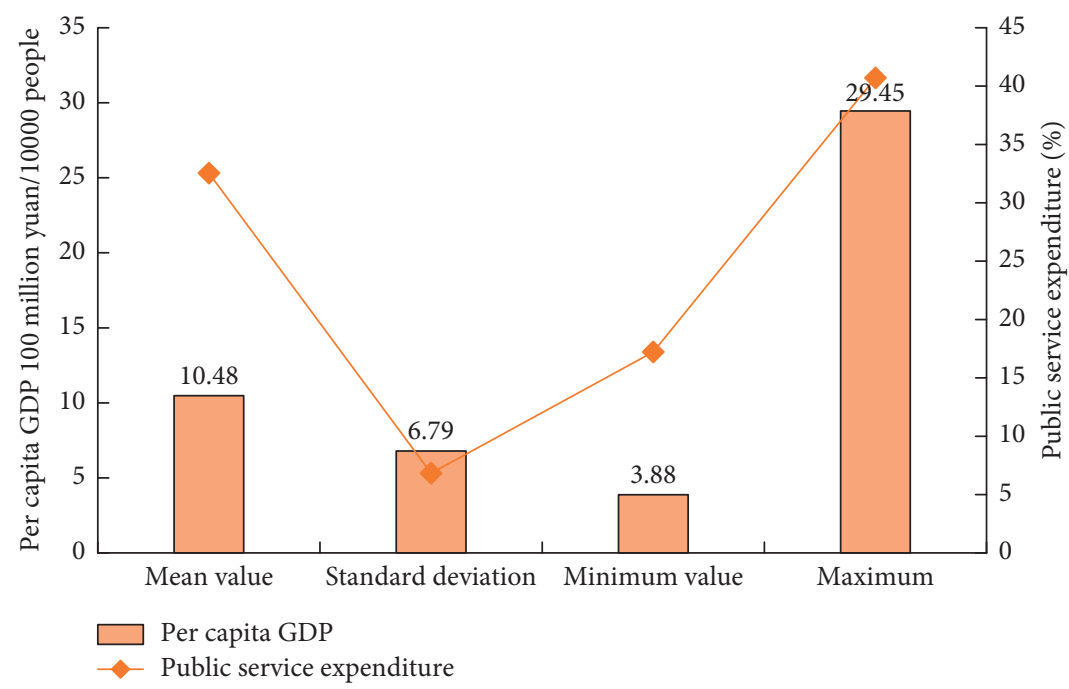

(b)

FIgURE 8: Subjective and objective variables. (a) Subjective variables. (b) Objective variables.

The final estimation result of variance component shows that the cross grade correlation coefficient is about 0.024 . In the total variance, the objective difference is only $2.4 \%$. Chi square test results show that the variance components of social service satisfaction have very significant differences. This confirms that objective factors can affect social service satisfaction to a certain extent, but the influence is relatively weak. The influence of objective factors on elderly social service satisfaction under fixed effect is shown in Figure 9. The initial regression coefficient was 67.511935. The regression coefficient of public service financial expenditure was -0.099134 , which had a weak negative effect on social service satisfaction $(P<0.05)$. When other variables were fixed, the higher the proportion of public service financial expenditure, the lower the corresponding social service satisfaction. This reflects the efficiency of public service investment and the psychological factors of elderly satisfaction with social services. To improve the performance of public services, we need not only to increase the investment in public services but also to ensure the effective use of the resources invested. The elderly evaluation of social service satisfaction is greatly affected by subjective factors, including age, occupation, gender, and many other factors. Population density, geographical location, and public service expenditure had no significant effect on social service satisfaction $(P>0.05)$.

The influence of subjective factors on social service satisfaction of the elderly is shown in Figure 10. There was a significant difference in gender satisfaction with social services $(P<0.05)$. The satisfaction scores of men and women were 68.0 and 67.7, respectively. The elderly's participation in public welfare activities, the elderly's awareness of government, and the elderly's participation 


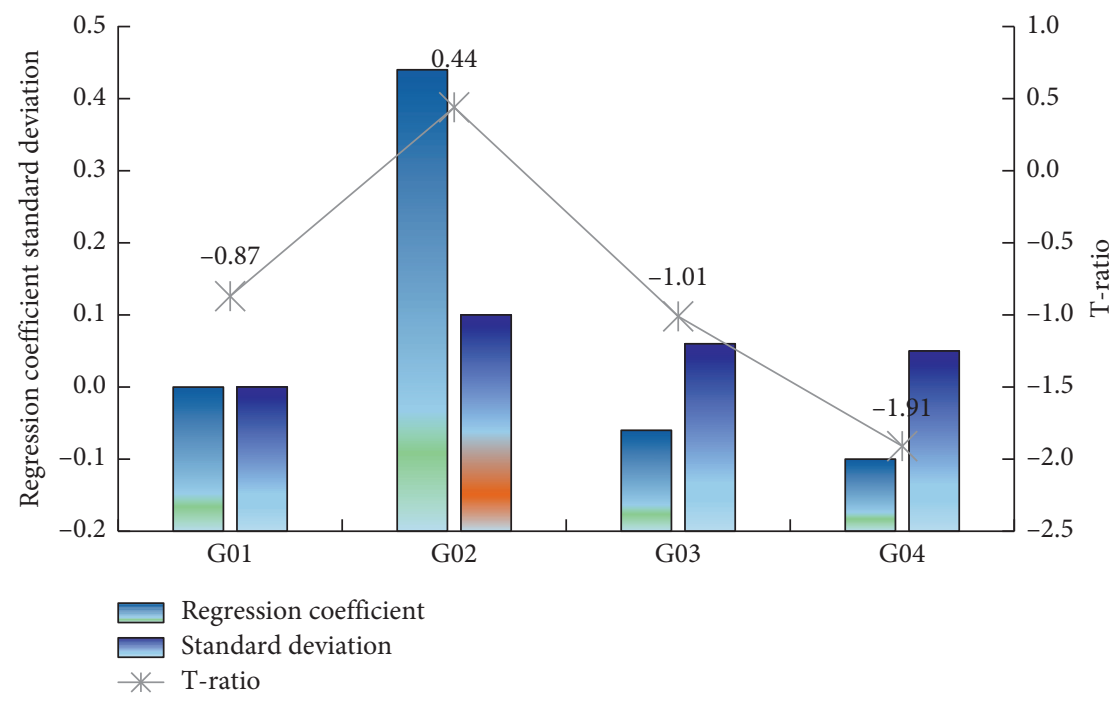

FIGURE 9: Results of the multilevel linear regression model of objective factors and social service satisfaction.

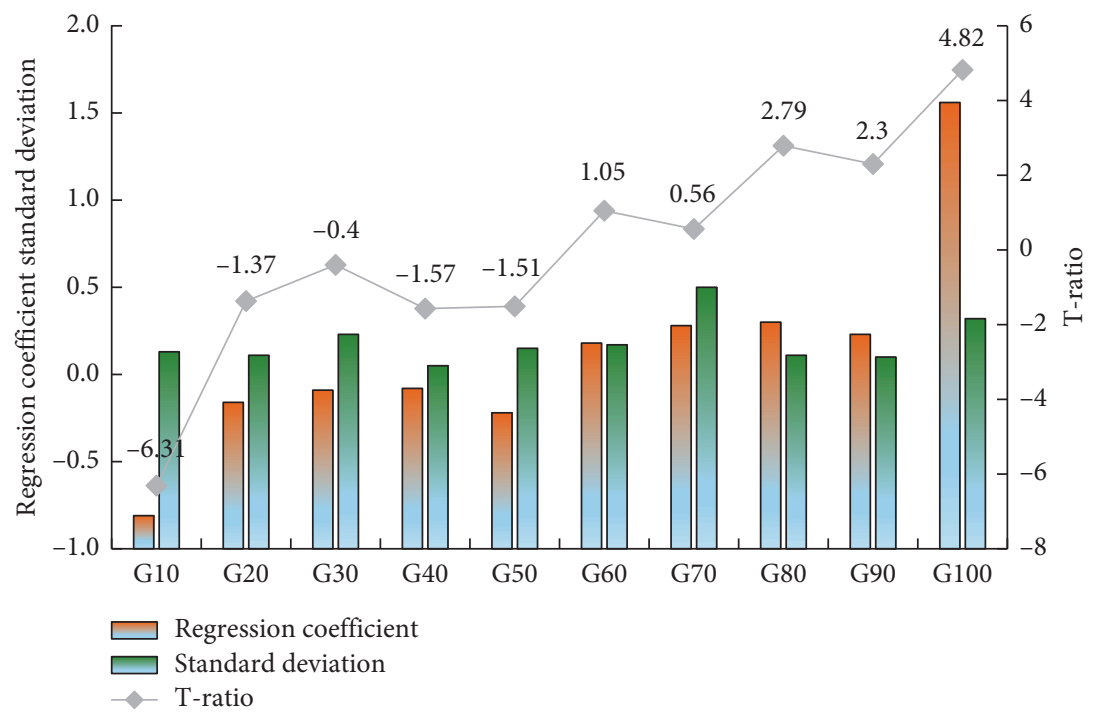

FIGURE 10: Results of multilevel linear regression model between subjective factors and social service satisfaction.

in government could significantly positively promote the satisfaction of social service $(P<0.05)$. This shows that the more active the elderly participate in public welfare activities, the higher their satisfaction with social services. The higher the awareness of government, the higher the satisfaction of social service. The more active the elderly participate in government, the higher their satisfaction with social services. Household registration, political background, monthly income, occupation, education level, and age had no significant effect on social service satisfaction $(P>0.05)$.

\section{Conclusion}

Based on the survey data of people's livelihood satisfaction of a province in 2018 , this paper constructs a social service satisfaction index model including 8 primary indicators and 16 secondary indicators and analyzes the impact of social satisfaction index on people's livelihood satisfaction from both subjective and objective levels. $Q$ District, $N$ District, $D$ District, and $L$ District ranked the top four in terms of social service satisfaction, with the scores of $72.90,70.93,70.78$, and 70.47 respectively, while $J$ District, $C$ District, $E$ District, 
and $H$ District ranked the bottom four with the scores of $65.97,65.56,65.51$, and 64.77 , respectively. The minimum and maximum standard deviations of satisfaction scores of each region were 9.72 and 13.63, respectively, but they all reached the pass level. The scores of education, medical treatment, housing, transportation, environment, sports, the rule of law, and efficiency were 69.66, 66.69, 63.29, 67.98, $66.99,68.97,69.55$, and 69.73, respectively. Public service expenditure has a weak negative effect on social service satisfaction, while population density, geographical location, and per capita GDP have no obvious effect on social service satisfaction. There is a significant gap between men and women on social service satisfaction. The elderly's participation in public welfare activities, the elderly's awareness of government, and the elderly's participation in government can significantly promote social service satisfaction. Household registration, political background, monthly income, occupation, education level, and age had no significant effect on social service satisfaction. Subjective factors have a strong impact on public service satisfaction and have a strong ability to explain the differences between districts and counties. The range of sample data is relatively small. The model of social service satisfaction evaluation needs further verification of large-scale data to improve the effectiveness and practicability of the model. In the future, the research needs to combine with many objective factors such as government to explore the satisfaction of social work service of the elderly.

\section{Data Availability}

The raw/processed data required to reproduce these findings cannot be shared at this time as the data also form part of an ongoing study.

\section{Conflicts of Interest}

The authors declare that they have no conflicts of interest.

\section{References}

[1] R. Jayalakshmi, S. Chatterjee, and D. Chatterjee, "End-of-life characteristics of the elderly: an assessment of home-based palliative services in two panchayats of Kerala," Indian Journal of Palliative Care, vol. 22, no. 4, pp. 491-498, 2016.

[2] H. E. Xinyu, S. Lee, and S. Lee, "Life satisfaction and social capital of the Chinese elderly," Asian Journal of Human Services, vol. 13, pp. 46-62, 2017.

[3] F. Hu, J. Li, W. Wang, and K. Sato, "Meaningful experience in service design for the elderly: SAPAD framework and its case study," Proceedings of the Design Society: International Conference on Engineering Design, vol. 1, no. 1, pp. 3081-3090, 2019.

[4] L. Gao, X. Cao, and M. Zhang, "The study on community health education of empty nest elderly," Engineering, vol. 05, no. 10, pp. 137-139, 2016.

[5] S. Marmo and C. Berkman, "Social ers' perceptions of job Satisfaction, Interdisciplinary Collaboration, and organizational leadership," Journal of Social in End of Life \& Palliative Care, vol. 14, no. 109, pp. 1-20, 2018.
[6] S. Utz and J. Breuer, "The relationship between use of social network sites, online social support, and well-being," Journal of Media Psychology, vol. 29, no. 3, pp. 115-125, 2017.

[7] Dan, Wang, Huilan et al., "Qualitative analyses of lived experience for residents in the elderly care departments at the community health service centres in Southwestern China," Health \& Social Care in the Community, vol. 26, no. 1, pp. 1-9, 2017.

[8] X. W. Chan, T. Kalliath, P. Brough, O.-L. Siu, M. P. O’Driscoll, and C. Timms, "Work-family enrichment and satisfaction: the mediating role of self-efficacy and work-life balance," The International Journal of Human Resource Management, vol. 27, no. 15, pp. 1755-1776, 2016.

[9] E. L. Lizano, "The impact of work-family conflict on psychological well-being: a cross-sectional study of Salvadoran social workers," Journal of Ethnic \& Cultural Diversity in Social Work, vol. 30, no. 7, pp. 1-11, 2020.

[10] A. Castro, M. M. Vitali, A. B. S. Bousfield, and B. V. Camargo, "Social representations of the internet for the elderly," Journal of Human Growth and Development, vol. 30, no. 2, pp. 227240, 2020.

[11] G. S. Mamo, "Assessment of the factors that affect customer satisfaction on service quality: a case study in ethio telecom dawro zone," Arabian Journal of Business and Management Review, vol. 8, no. 1, pp. 1-5, 2018.

[12] E. H. K. Yung, S. Wang, and C.-k. Chau, "Thermal perceptions of the elderly, use patterns and satisfaction with open space," Landscape and Urban Planning, vol. 185, pp. 44-60, 2019.

[13] N. Nursalam, M. C. Hanafi, and E. Ulfiana, "The elderly's satisfaction with the service quality of a community geriatric health programme in Indonesia: a cross-sectional study," Jurnal NERS, vol. 12, no. 2, pp. 225-232, 2017.

[14] H. Park, E. Jang, and S. Hong, "The influence of satisfaction with interpersonal relationships and social support on subjective health status among the elderly people living alone," Social Science Research Review, vol. 36, no. 2, pp. 1-19, 2020.

[15] K. Beyene, A. H. Y. Chan, N. S. Bandreddi et al., "Patient satisfaction with community pharmacist-led anticoagulation management services and its relationship with patient characteristics in New Zealand," International Journal of Clinical Pharmacy, vol. 43, no. 17, pp. 1-11, 2020.

[16] s f Shih and C. y Liao, "The development status and citizen satisfaction of smart cities in China," Journal of Global Business Management, vol. 7, no. 11, pp. 57-68, 2019.

[17] R. C. P. Wong, W. Y. Szeto, L. Yang et al., "Elderly users' level of satisfaction with public transport services in a high-density and transit-oriented city," Journal of Transport \& Health, vol. 11, Article ID S2214140516304121, 2017.

[18] K. Kazerooni, M. Pazokian, M. Nasiri et al., "Expectations and satisfaction of elderly people with health services provided at a public nursing home in Iran," Revista Latinoamericana de Hipertension, vol. 14, no. 1, pp. 95-101, 2019.

[19] M.-H. Jung, J. S. Moon, and J.-S. Moon, "A study on the effect of beauty service of the elderly on successful ageing: focused on mediated effect of self-esteem," The Journal of Asian Finance, Economics and Business, vol. 5, no. 4, pp. 213-223, 2018.

[20] J. Liao, L. Feng, and J. Huang, "A study on satisfaction of elderly care service quality based on different groups: taking the monitoring data of liaoning province as an example," SHS Web of Conferences, vol. 96, p. 02003, 2021. 